\title{
Genomic Orientation
}

National Cancer Institute

\section{Source}

National Cancer Institute. Genomic Orientation. NCI Thesaurus. Code C48673.

The orientation of a genomic element on the double stranded molecule. 